\section{Moneten fließen}

Die Weihnachtsvorbereitungen laufen auf Hochtouren. Und wie erste Prognosen bereits im November ankündigten, lohnt sich das jährliche Geschäft rund ums Christfest wieder ordentlich. Laut einer Umfrage der Beratungsgesellschaft EY wollen die Bürger in diesem Jahr 266 Euro für Weihnachtsgeschenke oder -gutscheine ausgeben. Das wären sieben Euro oder drei Prozent mehr als im Vorjahr. Außerdem wäre es die zweithöchste Summe der vergangenen zehn Jahre. Das bisherige Spitzenbudget von 273 Euro wurde der Umfrage zufolge 2013 ausgegeben.

\section{Musik ertönt}

Was mussten sich die Berliner in den vergangenen zehn Jahren nicht alles wegen ihres Hauptstadtflughafens BER anhören!? Die Milliarden verschlingende Dauerbaustelle sorgte für weltweites Gelächter. Aber andere können auch gut Geld verprassen: die Hamburger zum Beispiel. Für die kürzlich eröffnete Elbphilharmonie hat die Hansestadt stolze 866 Millionen Euro springen lassen. Soweit die offiziellen Zahlen. Und erhebliche Verzögerungen und Finanzierungsengpässe gab es beim Bau des prestigeträchtigen Konzerthauses auch. Was lange währt...

\section{Medizin spricht}

Auch wenn Kunst und Kultur die Sinne beflügeln, gibt es vielleicht doch den einen oder anderen Bereich, der eine prioritäre Finanzierung erfordert. Zum Beispiel das Gesundheitswesen. Und so haben die Haushaltspolitiker des Bundestages den deutschen Gesundheitsetat für 2017 auf rund 15 Milliarden Euro festgelegt. Davon gehen 14,5 Milliarden Euro in den Gesundheitsfonds. Die SPD-Fraktion behauptet auf ihrer Homepage, bei den Verhandlungen die gesundheitliche Beratung und Hilfe gestärkt zu haben. Der Gesamthaushalt des Bundes wird im nächsten Jahr 329,1 Milliarden Euro umfassen, das sind 12,2 Milliarden Euro mehr als 2016.

\title{
Frohe Weihnachten und einen guten Rutsch!
}

\author{
Zum Jahresende zieht die Menschheit für gewöhnlich Bilanz. Da \\ kommen Bilder des Jahres, Katastrophen des Jahres, aber auch die \\ schönsten Momente des Jahres noch einmal in Erinnerung. Ganz \\ frisch im Kurzzeitgedächtnis dürfte den Menschen ein Ereignis \\ sein, bei dem die Welt den Atem angehalten hat - die Wahl des \\ neuen US-Präsidenten.
}

Multimilliardär und Republikaner Donald Trump hat es geschafft. Und das finden außerhalb Amerikas eher wenige prickelnd. Auch wenn der Populist mit deutschen und schottischen Wurzeln sein extrovertiertes Auftreten nach der Wahl etwas heruntergefahren hat, den meisten Staatschefs ist der neue Mann im Weißen Haus sehr suspekt, um es gemäßigt auszudrücken. Wie sich Trump ab Januar 2017 als neuer Präsident anstellen wird, bleibt abzuwarten. Besser als unter Barack Obama wird es für Europa sicher nicht, darin sind sich alle Experten einig.

Auch in Deutschland stehen im nächsten Herbst Bundestagswahlen an. Die werden gewiss weniger aufregend als in den USA, aber dennoch spannend. In der Gesundheitspolitik kann die Koalition am Ende der Legislaturperiode einiges vorweisen. 2016 war ein gesundheitspolitisch bewegtes Jahr. Das zeigt auch der Jahresrückblick in dieser DFZ-Ausgabe ab Seite 18.

Das Schöne an einem Jahreswechsel ist jedoch, dass er die Gelegenheit bietet, alle Erlebnisse und Ereignisse der vergangenen zwölf Monate für einen Moment hinter sich zu lassen und die freie Zeit für sich, die Familie und Freunde zu nutzen. Das neue Jahr kommt, und mit ihm wieder tolle Momente genauso wie Tücken des Alltags. Das ist sicher.

Die DFZ-Redaktion wünscht Ihren Lesern ein frohes, besinnliches Weihnachtsfest, erholsame Feiertage und einen guten Rutsch ins Jahr 2017.

Melanie Fügner, Sabine Schmitt, Dr. Joachim Hüttmann (DFZ-Chefredakteur)

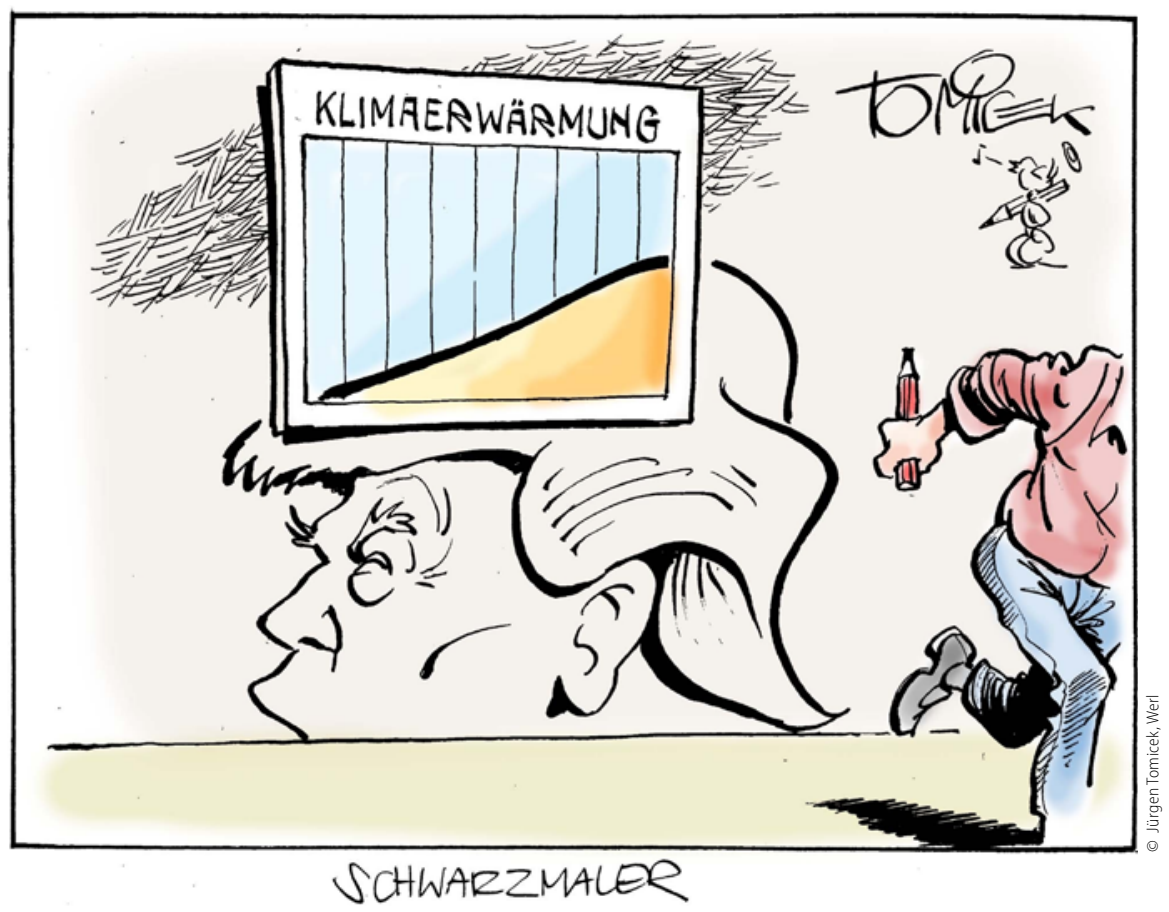

